\title{
Design of temperature control system for crystal silicon velvet
}

\author{
Qing Wang ${ }^{1, *}$, Lili Zhou ${ }^{1}$ \\ ${ }^{1}$ School of electrical \& energy engineering, Nantong Institute of Technology, China
}

\begin{abstract}
With the rapid development of automation control technology, the majority of enterprises have begun to introduce automation equipment, but in some photovoltaic cell production in the enterprise, for the crystal silicon pile of temperature control in the process is still in the traditional way of manual control, this way of temperature control for the employee's personal safety demand is higher, there is a certain risk. Aimed at this problem, this paper designed a crystal silicon velvet temperature control system based on $\mathrm{MCU}$, the system consists of DS18B20 temperature sensor, 51 single chip microcomputer, sound and light alarm system, LCD1602 display module and motor drive module, the implementation of the system of velvet groove temperature monitoring, to ensure that the quality of the crystal silicon cell, through the simulation test system is stable, reliable and has certain practical application and popularization value.
\end{abstract}

\section{Introduction}

At present, the biggest problem at home and abroad is the shortage of energy, and even many regions are facing the severe challenge of power crisis. In solving the contradiction between energy development, utilization, supply, consumption, economic and social development, China's situation is more serious. As an ideal renewable energy source, solar energy has attracted much attention in many countries. The types of crystalline silicon cells are becoming more and more diverse, and the application scope and market scale are also increasing. In recent years, the total production of crystal silicon cells in the world has increased by about $20 \%$ annually on average. China's photovoltaic enterprises have also experienced rapid development and formed a relatively complete industrial chain. As the basis of solar power generation, it is very important to produce high quality cells. In the process of production of crystalline silicon cells, there are many factors affecting the quality of the cell, the temperature is an important factor, in the process of crystal silicon velvet, each process has a certain temperature requirements, and in the process of crystal silicon velvet pile process, the temperature must be controlled in $80 \pm 5^{\circ} \mathrm{C}$, if below or above this temperature will affect the quality of the $\mathrm{s}$ crystal silicon velvet, will not be able to produce high quality batteries. This paper in view of the present situation, the new energy of crystalline silicon manufacturing at home and abroad research, specifically for crystalline silicon are manufacturing enterprises in the manufacturing process of the intelligent equipment the use of statistics, found that the factory is still in the process of temperature control with the method of primitive, or a way of temperature control based on manual operation, but this kind of control mode has certain problems, such as in some dangerous scenario, people need to bear the risk of a lot of work, and in the event of a problem when there is no way to stop in time. When the cell is mass-produced, there is a high requirement for the temperature of the solution in the flume, as there are many crystal silicon wafers to be processed. Originally, the chemical liquid circulation was mainly carried out through the auxiliary flume and the velvet flume to quickly remove the excess heat, and the solution in the velvet flume was prepared through the cooling water to control the temperature. However, this method is too traditional and cannot be applied to the process of crystal silicon velvet efficiently. Therefore, considering the existing problems of temperature controller, this paper designs a crystal silicon velvet temperature control system based on single chip microcomputer, which can break this traditional temperature control method and carry out temperature control efficiently.

\section{The making process of crystal silicon}

The fleece-making process, which can detect the temperature crystal silicon in the fleece-making flume at any time, it is to oxidize the silicon so that isotropic nonuniform corrosion occurs on the silicon surface, forming a hemispheric suede, which is conducive to reducing light reflection and enhancing light absorption. Its principle is to take advantage of the strong oxidation of nitric acid and the complexing property of hydrofluoric acid to oxidize and complexing silicon, resulting in isotropic non-uniform corrosion of the silicon surface, thus forming a similar "pit" shaped sutures. As far as crystal silicon velvet is concerned, excessive temperature will affect the quality of velvet. Therefore, the velvet temperature should be controlled within a certain range $\left(80 \pm 5^{\circ} \mathrm{C}\right)$, so that the most ideal process effect can be achieved and photovoltaic cells with high efficiency can

\footnotetext{
* Corresponding author: qingwang2012@,126.com
} 
be produced. Temperature is an important factor in the quality of the battery.

Crystalline silicon cells are divided into polycrystalline silicon and monocrystalline silicon. The monocrystalline silicon is as shown in Fig. 1. The polycrystalline silicon is as shown in Fig. 2.
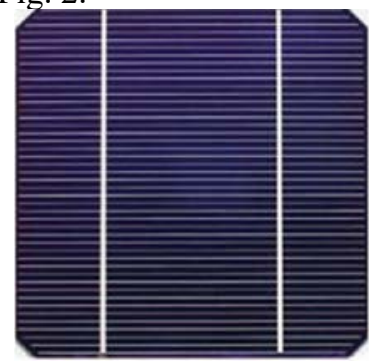

Fig. 1. Monocrystalline Silicon Cells.

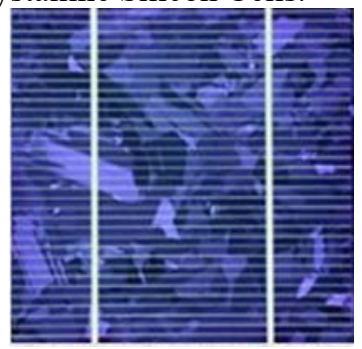

Fig. 2. Polycrystalline Silicon Cells.

The preparation process of crystal silicon cell has certain temperature requirement, including the temperature of the specific requirements for the system velvet slot in $80 \pm 5^{\circ} \mathrm{C}$, diffusion oxidation temperature is $800-1000^{\circ} \mathrm{C}$, etching temperature requirements at around $40{ }^{\circ} \mathrm{C}$, silk screen printing to ambient temperature of $25 \pm 3{ }^{\circ} \mathrm{C}$, the peak of the sintering temperature for $760 \pm 10{ }^{\circ} \mathrm{C}$, so the temperature control within the scope of these can guarantee the high quality of the cells. The temperature control system designed in this paper is mainly used in the process of making velvet.

At present, the temperature control system for making velvet in enterprises generally adopts the manual control mode, namely cooling water to control the temperature, The Cooling water temperature-controlled is as shown in Fig. 3.

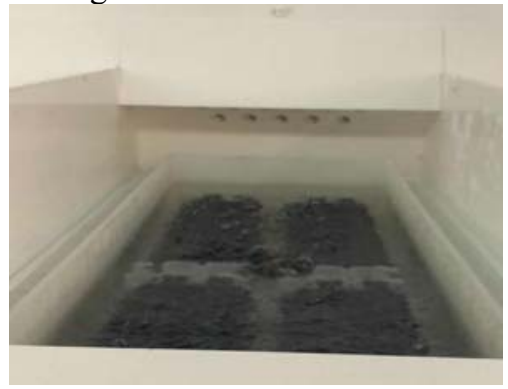

Fig. 3. Cooling Water Temperature-controlled

In order to achieve the ideal velvet effect, the velvet temperature must be controlled within the normal range, otherwise the best velvet surface cannot be formed, and cannot produce high-quality battery. The following is the surface diagram of velvet making under the conditions of too low temperature is as shown in Fig. 4, normal temperature is as shown in Fig. 5 and too high temperature is as shown in Fig. 6.

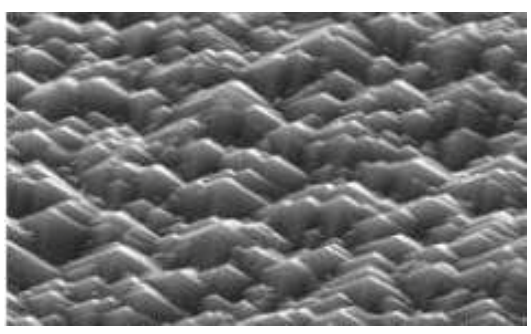

Fig. 4. Too Low Temperature for Making Velvet

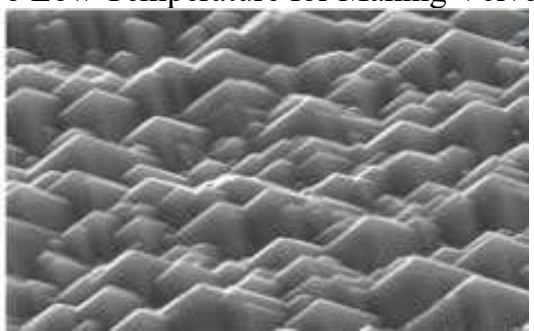

Fig. 5. Normal Temperature for Making Pile

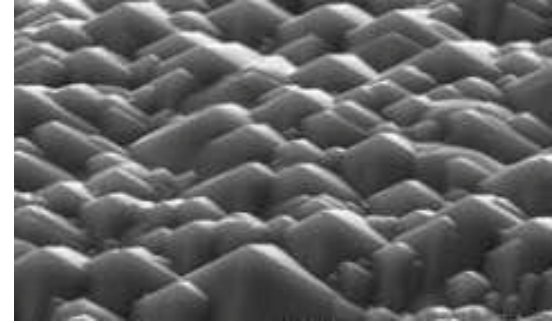

Fig. 6. Too High Temperature for Making Velvet

As the comparison of the above three Fig.s, neither too high temperature nor too low temperature can make the pyramid shape of crystal silicon surface form the best state and form the best sutured surface, which greatly affects the quality of crystal silicon cell.

\section{Overall design of system}

The temperature control system of crystal silicon velvet based on single chip microcomputer mainly designs the minimum system of single chip microcomputer, DS18B20 temperature sensor circuit, motor rotation temperature regulation circuit, ound and light alarm circuit and LCD1602 display circuit. The overall block diagram of the system is as shown in the Fig. 7.

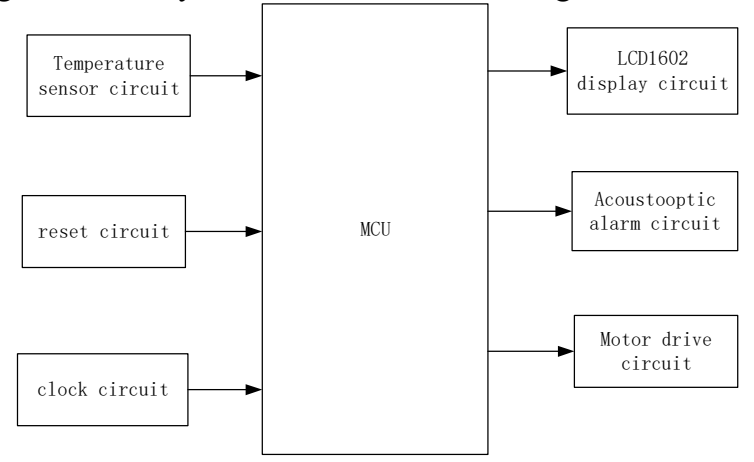

Fig. 7. Overall System Design Drawing

The user through the sound and light alarm circuit and LCD1602 display circuit can be detected temperature in the flume at any time. when the system detects the temperature more than or less than $80 \pm 5^{\circ} \mathrm{C}$, the timely will trigger the sound and light alarm circuit 
and motor drive circuit to control the temperature, thus the temperature control to the desired range.

\subsection{System hardware circuit design}

In the temperature regulation part, this design uses two parts to realize the temperature control function. One part is heating device, the other part is cooling device. The cooling device mainly drives the DC motor to drive the exhaust system for cooling, while the heating is carried out by the electric heating device.

The working principle of the motor circuit in the cooling device is relatively simple, when a certain current is fed into the motor, the magnetic field on the motor will be triggered. Since the direction of the magnetic core inside the motor is the same as the direction of the magnetic field generated by the current, and because of the principle of same kind of repulsive, the rotation axis of the motor will rotate. Generally, the motor we commonly use is a DC motor. After direct current is switched into the motor, it can be rotated. The main difficulty of the motor circuit lies in the design of the drive circuit, because the motor rotation will have a certain feedback on the superior circuit, affecting the work of the control circuit. Therefore, it is necessary to design the corresponding isolation circuit to avoid the influence of the motor on the MCU. This design chooses L298 drive circuit to carry on the control to the motor. The inputoutput relationship of L298 is shown in the table 1.

Table 1. L298N Input/Output Relationship Table

\begin{tabular}{|c|c|c|c|}
\hline ENA & IN1 & IN2 & $\begin{array}{c}\text { Motor running } \\
\text { state }\end{array}$ \\
\hline H & H & L & Motor forward \\
\hline H & L & H & motor reverses. \\
\hline H & H & H & motor stop \\
\hline L & X & X & motor stopped \\
\hline
\end{tabular}

According to the input-output relationship of L298N, the control terminal ENA is connected to P3.0 port of AT89C51 and connected to oscilloscope to display duty ratio. I/O port $\mathrm{P} 3.1$ and $\mathrm{P} 3.2$ of $\mathrm{MCU}$ are connected to IN1 and IN2 of L298N respectively to control the positive and negative rotation of the motor (IN1 of the input terminal is PWM signal, IN2 of the input terminal is low level, and the motor is in positive rotation;Input terminal IN2 is PWM signal, input terminal IN1 is low level, and the motor reverses). The speed of the motor is realized by the single-chip microcomputer to adjust the duty ratio of PWM signal. This design uses $12 \mathrm{~V}$ dc motor, Motor drive schematic diagram is as shown in Fig. 8.

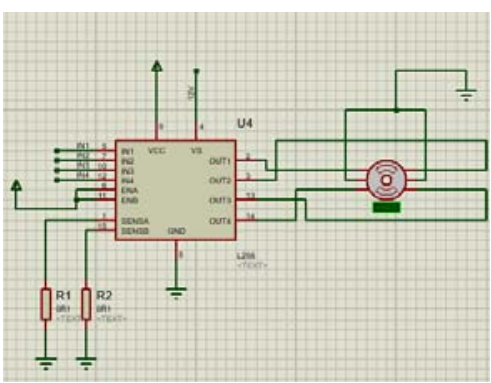

Fig. 8. Motor Drive Schematic Diagram

The speed of the DC motor is related to two factors: the excitation flux and the input voltage. The relationship between them is shown as equation 1

$$
\mathrm{n}=\mathrm{U}-(\mathrm{IR}+\mathrm{L} * \mathrm{di} / \mathrm{dt}) / \mathrm{K} \varphi
$$

The above equations represents the motor speed, where $\mathrm{U}$ is the calculation formula of armature voltage, I is the armature current, $\mathrm{R}$ is the resistance of armature circuit, is the magnetic flux, and $\mathrm{K}$ is the induction constant. It is usually realized by changing $U$ when changing the speed of the motor. This design uses MCU to generate PWM wave to control the speed of the motor.

\subsection{System software design}

The temperature alarm system is mainly controlled by the MCU through the high and low level state of $\mathrm{P} 2 \wedge 2$ port to determine whether the buzzer works. When $\mathrm{P} 2 \wedge 2$ pin is at high voltage, sound and light alarm system. Otherwise, the buzzer will not alarm and the red light will be put out. The temperature range is set internally when the system is designed and programmed. In this system, the upper limit temperature is $85^{\circ} \mathrm{C}$, while the lower limit temperature is $75^{\circ} \mathrm{C}$. When the temperature is higher than $85^{\circ} \mathrm{C}$, the relay drives the motor to take cooling measures. When the temperature is lower than $75^{\circ} \mathrm{C}$, the relay drives the power to take heating measures. when $\mathrm{P} 2^{\wedge} 0$ is low, the system heats up. When $\mathrm{P} 2 \wedge 1$ is low, the system cools down. The subroutine of temperature treatment and alarm system is as shown in Fig. 9.

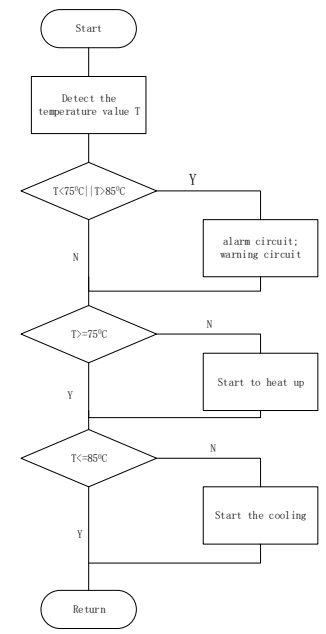

Fig. 9. Flow Chart of Temperature Handling and Alarm System 


\section{System hardware and software coordination}

The temperature signal acquisition module mainly uses the temperature sensor DS18B20 to collect the temperature in the pile making flume and send the temperature data collected to the MCU. AT89C51 microcontroller temperature sensor transmitted to the temperature value after processing, the data sent to LCD, and then LCD display after processing temperature value. The temperature handling module is controlled by a relay, which is connected with a motor to heat or cool the temperature separately. Liquid crystal temperature display module displays the current value of temperature. When the measured temperature is above or below $80 \pm 5^{\circ} \mathrm{C}$, the sound and light alarm system will give an alarm, at which time the buzzer will ring and the red light will be lit.

The normal temperature range set by this system is $75^{\circ} \mathrm{C}$ $\sim 85^{\circ} \mathrm{C}$. Within this temperature range, the system works normally, and the alarm system, heating device and cooling device do not work. When it is lower than $75^{\circ} \mathrm{C}$, both the heating device and the alarm system work. When it is higher than $85^{\circ} \mathrm{C}$, both the cooling device and the alarm system work. When the system temperature is $80^{\circ} \mathrm{C}$, the simulation results are shown in Fig. 10 .

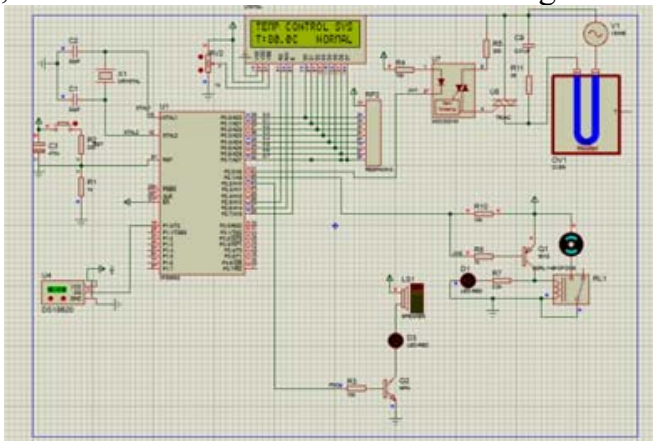

Fig. 10. Normal Temperature Control Chart

When the temperature detected by the temperature acquisition module is above $85^{\circ} \mathrm{C}$, the buzzer rings and the red light is on, and the cooling device works. The simulation results are shown in Fig. 11.

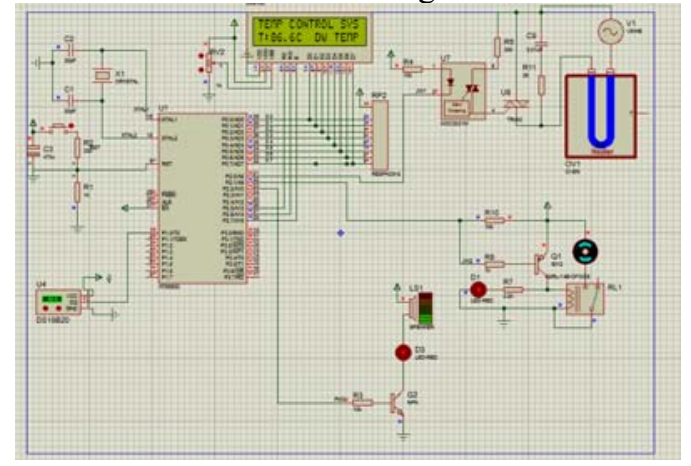

Fig. 11. Cooling and Alarm Diagram

When the temperature detected by the temperature acquisition module is lower than $75^{\circ} \mathrm{C}$, the buzzer rings and the red light is lit. The heating device is heated and displayed as magenta. The simulation results are shown in Fig. 12.

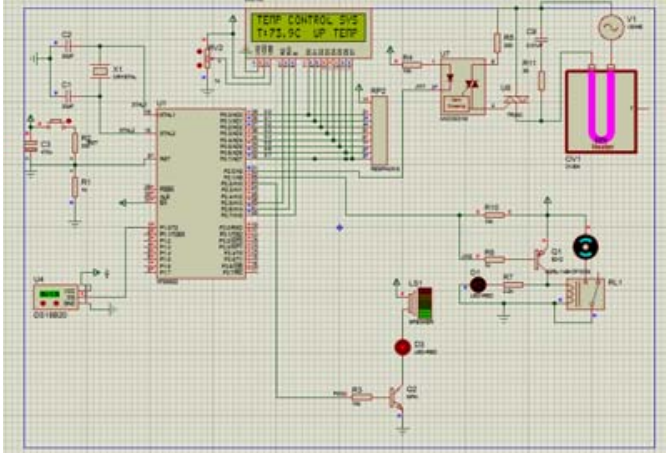

Fig. 12. Heating and Alarm Diagram

\section{Conclusion}

The flume is filled with high-risk chemical solutions, which are mixed into a liquid to corrode the surface of the crystal silicon wafers and form the suede. Using DS18B20 temperature sensor to measure the temperature can avoid the occurrence of dangerous accidents, which greatly enhances the safe and efficient production of crystal silicon cells. This thesis mainly includes temperature acquisition circuit, temperature alarm circuit, temperature regulation circuit and temperature display circuit. Through the design of module circuit, the temperature state in the flume can be monitored in real time. Through simulation test, the temperature control system of crystal silicon velvet based on single chip microcomputer is stable and reliable. Compared with the scheme based on manual control in current battery manufacturing enterprises, this system has certain practical application and promotion value.

\section{Acknowledgment}

This work was supported by the Young and middle-aged scientific research backbone of NanTong Institute of Technology under Grant No. ZQNGG306.

\section{References}

1. Q.Wang, Y.Qin, T.Y.Li, E3S Web of Conferences. ICAEER2018 53, 1026(2018)

2. X.1.Liu.Wind Power.Solar Energy.1082(2009)

3. K.A.D , MPPT Method for PV System.Electric Power Systems Research.975(2009)

4. N.Johnstone, I.Haščič,D.Popp. Environmental and Resource Economics. 68(2017)

5. A. Maleki, A. Askarzadeh, Sustainable Energy Technologies and Assessments.147(2014)

6. Q.Wang, T.Y.Li, Y.Chen, X.X.Xie, A.Pan, Design of micro solar power generation system .E3S Web of Conferences. ICAEER2019 118, 2063(2019) 